\title{
O papel da enfermagem diante da homossexualidade masculina
}

Leonardo Magela Lopes Matoso ${ }^{1}$

\begin{abstract}
RESUMO
O artigo objetiva discutir as contribuições da enfermagem diante da saúde do homossexual do gênero masculino. Trata-se de uma revisão integrativa, utilizando as bases de dados BEDEFN, LILACS e MEDLINE. A busca dos artigos foi realizada através dos descritores controlados: Enfermagem, Homossexualidade, Sexualidade e Identidade de Gênero. A amostra constitui-se de 11 artigos, onde os critérios de inclusão foram artigos completos, artigos em Português, artigos que abordassem a temática proposta. Evidencia-se que a enfermagem trabalha com elementos da promoção a saúde, através das orientações e da escuta qualificada. O cuidado de enfermagem visa promover a atenção integral à saúde do homem, através da promoção em saúde e pautado na Politica Nacional de Atenção Integral a Saúde do Homem (PNAISH). Porém, emerge o despertar para um cuidar que acolha homossexuais, travestis e transexuais. Precisa-se acolher dentro dos preceitos da afetividade, da ética e respeito, considerando a garantia de privacidade e liberdade.
\end{abstract}

Descritores: Enfermagem; Homossexualidade; Sexualidade; Identidade de Gênero.

\section{The role of nursing in front of male homosexuality}

\begin{abstract}
The article discusses the contributions of nursing on the health of homosexual males. This is an integrative review, using bases BEDEFN, LILACS and MEDLINE databases. A search of the literature was conducted through controlled descriptors: Nursing, Homosexuality, Sexuality and Gender Identity. The sample consisted of 11 items, where the inclusion criteria were full articles, articles in Portuguese, papers discussing the proposed theme. It is evident that nursing works with elements promoting health through the guidelines and qualified hearing. Nursing care aims to promote comprehensive health care of man, by promoting health and guided by the National Policy for Integral Attention to Men's Health (PNAISH). However, the awakening emerges for care that embraces homosexuals, transvestites and transsexuals. One must welcome within the precepts of affection, ethics and respect, considering the guarantee of privacy and freedom.
\end{abstract}

Descriptors: Homosexuality; Nursing; Sexualit; Gender Identity. 


\section{Introdução}

Para discutir sobre a saúde do homem, especificamente sobre a Homossexualidade masculina, se faz necessário proferir um recorte sobre o conceito de gênero, uma vez que as implicações advindas das desigualdades entre os sexos e a vivencia da sexualidade humana ainda estão bastante presente na sociedade contemporânea. Sendo assim, inicialmente abordaremos os conceitos de gênero, homossexualidade, sexualidade humana e heteronormatividade como um breve resgate teórico/ conceitual.

Destaca-se que o estudo do gênero surgiu mediante movimentos feministas na década de 70 e depois foi ganhando autonomia nas ciências sociais e humanas atingindo hoje status mais consistente.

Alguns autores ${ }^{2 ; 3}$ conceituam gênero como sendo um elemento constitutivo das relações sociais fundadas sobre as diferenças percebidas entre os sexos, sendo assim uma construção social historicamente determinada sobre os corpos sexuados.

Nessa ótica, com base nas diferenças corporais, sexuais e biofisiológicos, a sociedade cria padrões do que é próprio para o feminino e para o masculino e vai reproduzindo estas regras como se fosse um comportamento natural. São as chamadas representações de gênero. Sendo assim, a questão de gênero está ligada à forma como a sociedade cria os diferentes papéis sociais e comportamentos relacionados aos homens e às mulheres.

Portanto, ao se falar em gênero, não se fala apenas de macho ou fêmea, mas de masculino e feminino, em diversas e dinâmicas masculinidades e feminilidades. Gênero remete-se a construções sociais, históricas, culturais e políticas que dizem respeito ao que são socialmente definidos como homens e mulheres e o que é - e o que não é - considerado de homem ou de mulher, nas diferentes sociedades e ao longo do tempo ${ }^{1}$. Destaca-se que os homens e mulheres que fugiam do modelo de gênero estabelecido sofriam preconceitos e discriminação na sociedade.

Durante muito tempo, a psicanálise e a medicina, consideraram a homossexualidade como doença, tanto que era tratada por "homossexualismo" em que o sufixo "ismo" conferia uma idéia patológica sendo, dessa forma, tratado como tal. Em 1975, foi inserido na Classificação Internacional das Doenças - CID, como sendo um transtorno sexual. Em 1985, a Organização Mundial de Saúde - OMS informou que o homossexualismo deixava de ser uma doença, passando a ser considerado um desajustamento comportamental. Mas foi em 1995, que o homossexualismo deixou de ser considerado um distúrbio psicossocial e conseqüentemente deixou de constar no CID, sendo substituído o sufixo ismo pelo sufixo "dade", que passou a significar "modo de ser"1;:2.

Anterior a esse momento, a naturalização da heterossexualidade e as explicações biologicista e religiosas que compreendem, respectivamente, a homossexualidade como pertencente ao quadro das patologias e condenam essa prática, afirmando ser pecado fazendo com que, até meados do século XX, o preconceito sexual e as práticas discriminatórias frente às minorias sexuais, os quais formam o grupo LGBT (Lésbicas, Gays, Bissexuais, Travestis, Transexuais e Transgêneros), fossem negligenciados².

Contudo, buscar romper com essa barreira de preconceitos e discriminações no qual coloca a heterossexualidade como algo naturalizado é de suma importância em nossa sociedade.

Com relação à sexualidade humana, a mesma pode ser definida como uma energia que nos motiva a procurar amor, contato, ternura e intimidade; que se íntegra no modo como nos sentimos, movemos, tocamos e somos tocados; é serse sensual e ao mesmo tempo sexual, ela influência pensamentos, sentimentos, ações e interações e, por isso, influência também a nossa saúde física e mental. A sexualidade assume ao longo da nossa existência, uma enorme importância, uma vez que ela é parte essencial da nossa personalidade e da nossa vida ${ }^{2 ; 3}$.

Desta forma, compreende-se por sexualidade como sendo um conjunto de valores e práticas corporais culturalmente legitimados na história da humanidade. Mais do que pertinente à atividade sexual e sua dimensão biológica, ela diz respeito a uma dimensão íntima e relacional que compõe a subjetividade das pessoas e suas relações com seus pares e com o mundo ${ }^{1 ; 3}$.

Alguns autores afirmam ${ }^{1 ;: 5}$ que o modelo hegemônico de masculinidade diante da sexualidade impõe parâmetros para os heterossexuais, que no caso dos homens os levam a afirmarem sua sexualidade e virilidade a partir de comportamentos agressivos. Assim, para a construção de uma identidade masculina, é demandado a recusa aos papéis sociais comumente relacionados ao feminino, como a delicadeza ou a emoção. Além de negar esse estereótipo, é assumido como mecanismo psicológico, o insulto àquele homem heterossexual que foge a regra e viola o perfil do ser masculino. As humilhações sexistas é um desses mecanismos.

As minorias sexuais, dentre estes, o homossexual do gênero masculino, sofrem rotineiramente atos discriminatórios e estigmas sociais cheios de violência física, verbal, psicológicas e ainda são impelidos de exercerem suas funções como 
cidadãos na sociedade. Frente esse quadro, observa-se que a enfermagem encontra-se um pouco afastada dessa realidade e muita das vezes não consegue lidar com esse tipo de público ${ }^{6}$.

Dentro do exposto, emerge a proposta da Política Nacional de Atenção Integral à Saúde do Homem (PNAISH) na qual visa qualificar a saúde da população masculina na perspectiva de linhas de cuidado que resguardem a integralidade da atenção.

Em seu objetivo especifico, a PNAISH em seu capítulo oito, relativo há estimulação da implantação e implementação da assistência em saúde sexual e reprodutiva traz a "promoção da atenção integral à saúde do homem nas populações indígenas, negras, quilombolas, gays, bissexuais, travestis, transexuais, trabalhadores rurais, homens com deficiência, em situação de risco, em situação carcerária, entre outros, desenvolvendo estratégias voltadas para a promoção da equidade para distintos grupos sociais"2.

Evidencia-se que esta política não engloba a saúde do homossexual do gênero masculino em suas especificidades, de forma equitativa, humanizada e ética; por outro lado, ela trabalha com questões machistas e heteronormativa, onde a homossexualidade só foi contemplada em uma única linha durante toda a política.

Devido à lacuna que permeia esta política, o Ministério da Saúde, criou a Política Nacional de Saúde Integral de Lésbicas, Gays, Bissexuais, Travestis e Transexuais, onde o objetivo seria promover a saúde integral dessas minorias sexuais, eliminando a discriminação e o preconceito institucional, bem como contribuindo para a redução das desigualdades e a consolidação do Sistema Único de Saúde (SUS)S como sistema universal, integral e equitativo.

Segundo Mandu', a assistência profissional do enfermeiro na consulta à saúde do homem deve amparar-se em uma abordagem integral do indivíduo, ou seja, deve contemplar o mais amplamente possível os aspectos biológicos, sociais, subjetivos e de comunicação pertinentes às experiências da sexualidade, à autopercepção corporal, às trocas afetivas e relacionais humanas significativas, lidando com vulnerabilidades, potencialidades, necessidades e/ou problemas relacionados.

Sendo a educação em saúde, uma das ferramentas utilizadas para a mudança da qualidade de vida do ser humano é importante que o enfermeiro no contexto do cuidado e das orientações objetive prestar uma assistência integral e humanizada, pautado nas politicas públicas, principalmente na politica LGBT, por trabalhar esse público especifico. Objetivando promover a saúde integral e eliminando a discriminação e o preconceito, contribuindo dessa forma para a redução das desigualdades.

Diante do exposto elenca-se o seguinte questionamento: Quais as ações da enfermagem frente às questões que perpassam a saúde do homossexual do gênero masculino?

Sendo assim, o objetivo desse artigo é discutir o papel da enfermagem diante da saúde do homossexual do gênero masculino.

Vale salientar que optou-se por não trabalhar o papel da enfermagem na perspectiva do modelo piramidal, pois acredita-se que o papel, bem como a assistência de enfermagem deve ser dada através das redes, como uma organização circular e não hierárquica.

Destarte, torna-se importante discutir esse estudo, pois compreende-se que o enfermeiro no âmbito do cuidado e das orientações aos sujeitos deve visar apreender sobre o universo que perpassa a vida do homossexual, uma vez que esta é marcada ainda por inúmeros preconceitos, tabus e discriminações.

Espera-se que este artigo sensibilize a conduta de enfermagem quanto às ações realizadas na saúde do homossexual do gênero masculino; exercendo um cuidado autêntico, com respeito e sem preconceito, pois esta ação é possível, é humanizante e resgata a cidadania.

Nesse ínterim, humanizar significa reconhecer o ser que existe em cada sujeito que cuidamos, e ao prestar esse cuidado, olhar o sujeito não como um ser equânime, e sim um ser humano que necessita do nosso cuidado, respeitando cada um em sua individualidade, sexualidade e principalmente levando em conta suas especificidades.

\section{Metodologia}

Para elaboração da presente revisão integrativa foram seguidas as etapas preconizadas na literatura, a saber: 0 estabelecimento das questões e objetivos da revisão integrativa; estabelecimento dos critérios de inclusão e exclusão de artigos e outros documentos; definição das informaç̃̃es a serem extraídas dos materiais selecionados; análise dos resultados; discussão e apresentação dos resultados; e, por última, a apresentação da revisão.

A pergunta norteadora dessa revisão integrativa constituiu-se em: Quais as ações da enfermagem frente às ações da saúde do homossexual do gênero masculino? 
A seleção dos artigos foi por meio das bases de dados da Literatura Latino Americana e do Caribe em Ciências da Saúde (LILACS); Base de Dados em Enfermagem (BDENF); e MEDLINE. Dessa forma, procurou-se ampliar o âmbito da pesquisa, minimizando possíveis vieses nessa etapa do processo de elaboração do estudo.

Para o levantamento dos artigos nos bancos de dados, utilizaram-se os descritores controlados: Homossexualidade, Enfermagem, Sexualidade, Identidade de Gênero.

Os critérios de inclusão foram: Artigos completos disponíveis gratuitamente on-line; Artigos disponíveis no idioma Português; Artigos que abordassem a temática proposta. Não foram aplicados critérios no que dizem respeito às datas de publicação, pois nas bases de dados trabalhadas existe uma escassez no que se refere à temática em estudo. Os critérios de exclusão dos estudos foram: Monografias, Editoriais; Cartas ao editor; Artigos em outros idiomas; Artigos que não abordassem a temática relevante ao alcance do objetivo da revisão integrativa.

A busca foi realizada pelo acesso on-line, utilizando os descritores em português, e os critérios de inclusão e exclusão. Inicialmente na busca dos descritores associados, foram encontrados no LILACS 125 artigos, no BDENF ${ }^{5}$ e MEDLINE ${ }^{21}$. Após 0 atendimento aos critérios de inclusão e exclusão, a amostra foi constituída de 11 artigos.

Para a síntese e análise dos dados, foi elaborado um instrumento, que contempla os seguintes itens: identificação, autores, ano de publicação, título do artigo e objetivo.

A apresentação e discussão dos resultados foram feitas de forma descritiva, possibilitando ao leitor a avaliação da aplicabilidade da revisão integrativa elaborada, de forma a atingir o objetivo desse método, ou seja, impactar positivamente na qualidade da prática de enfermagem, fornecendo subsídios ao enfermeiro na docência e na prática assistencial cotidiana.

\section{Resultados}

A amostra final foi composta por onze artigos nas três bases de dados escolhidas onde preencheram os critérios de inclusão utilizados para qualificar as publicações no processo de busca bibliográfica. Os artigos apresentados na tabela a seguir constituíram o corpus deste estudo.

TABELA 1 - Distribuição dos artigos que constituem o corpus do estudo segundo identificação, autores, ano de publicação, título e objetivo.

\begin{tabular}{c|c|c|c|c}
\hline Ident. & Autor (es) & Ano & Título & Objetivo \\
\hline 1. & Nogueira JÁ, Almeida AS. & 2011 & $\begin{array}{c}\text { Diversidade sexual no contexto } \\
\text { escolar: percepção e atitudes dos } \\
\text { educadores. }\end{array}$ & $\begin{array}{c}\text { Analisar a percepção e as atitudes } \\
\text { dos educadores do ensino } \\
\text { fundamental quanto à diversidade } \\
\text { sexual no cenário escolar. }\end{array}$ \\
\hline 2. & Paiva V, Aranha F, Bastos F. & 2008 & $\begin{array}{c}\text { Opiniões e atitudes em relação à } \\
\text { sexualidade: pesquisa de âmbito } \\
\text { nacional, Brasil 2005. }\end{array}$ & $\begin{array}{c}\text { Descrever opiniões e atitudes } \\
\text { sobre sexualidade da população } \\
\text { urbana brasileira. }\end{array}$ \\
\hline 3. & Rios LF. & 2008 & $\begin{array}{c}\text { Corpos e prazeres nos circuitos de } \\
\text { homossociabilidade masculina do } \\
\text { Centro do Rio de Janeiro }\end{array}$ & $\begin{array}{c}\text { Analisar por meio da pesquisa } \\
\text { etnográfica as bases culturais que } \\
\text { orientam a sexualidade. }\end{array}$ \\
\hline 4. & Palma YA, Levandowsk DC. & 2008 & $\begin{array}{c}\text { Vivências pessoais e familiares de } \\
\text { homossexuais femininas. }\end{array}$ & $\begin{array}{c}\text { Descrever as vivências pessoais } \\
\text { e familiares de homossexuais } \\
\text { femininas. }\end{array}$ \\
\hline 5. & Silva, LMP. & 2008 & $\begin{array}{c}\text { Experiências plurais em cate- } \\
\text { gorias singulares: Problema- } \\
\text { tizandoa materialização das } \\
\text { travestilidades. }\end{array}$ & $\begin{array}{c}\text { Relatar a experiência de } \\
\text { alunos durante a durante a 1a } \\
\text { Conferência Nacional de LGBT. }\end{array}$ \\
\hline 7. & Menezes ABC, Brito RCS. & 2007 & $\begin{array}{c}\text { Trajetória de vida de um } \\
\text { homossexual: entre o silêncio e a } \\
\text { opressão }\end{array}$ & $\begin{array}{c}\text { Descrevaro sobre a } \\
\text { oral a vida de um homossexual do } \\
\text { gênero masculino. }\end{array}$ \\
\hline 6. & Simpson CA, et al. & 2007 & $\begin{array}{c}\text { Discutir a hipótese de } \\
\text { determinação genética da } \\
\text { homossexualidade. }\end{array}$ \\
\hline
\end{tabular}




\begin{tabular}{c|c|c|c|c}
\hline 8. & $\begin{array}{c}\text { Salomé GM, Espósito VHC, } \\
\text { Moraes ALH. }\end{array}$ & 2007 & $\begin{array}{c}\text { O significado de família para } \\
\text { casais homossexuais. }\end{array}$ & $\begin{array}{c}\text { Compreender a estrutura e a } \\
\text { dinâmica da família de casais } \\
\text { constituída por pessoas do mesmo } \\
\text { sexo, a partir de como ela é } \\
\text { vivenciada. }\end{array}$ \\
\hline 9. & Mandú ENT. & 2004 & $\begin{array}{c}\text { Consulta de enfermagem na } \\
\text { promoção da saúde sexual. }\end{array}$ & $\begin{array}{c}\text { Discutir a consulta de enfermagem } \\
\text { na promoção da saúde sexual do } \\
\text { homossexual masculino. }\end{array}$ \\
\hline 10. & Rios LF. & 2003 & $\begin{array}{c}\text { Parcerias e práticas sexuais de } \\
\text { jovens homossexuais no Rio de } \\
\text { Janeiro }\end{array}$ & $\begin{array}{c}\text { Abordar os aspectos da } \\
\text { organização das vidas eróticas } \\
\text { de homens jovens com práticas } \\
\text { homossexuais. }\end{array}$ \\
\hline 11. & Scott J. & 1989 & $\begin{array}{c}\text { Gênero: uma categoria útil para } \\
\text { análise histórica. }\end{array}$ & $\begin{array}{c}\text { Discutir os aspectos conceituais } \\
\text { de gênero, sexualidade } \\
\text { e identidade sexual da }\end{array}$ \\
\hline
\end{tabular}

Dentre os artigos selecionados o período de publicação variou entre os anos de 1989 a 2011. Todos os artigos se referiam à homossexualidade, gênero, sexualidade e as minorias do público, entretanto, apenas um trabalhava a enfermagem e suas ações diante desse público.

Verificou-se que oito dos estudos possuem objetivos claros possibilitando um fácil entendimento ao leitor. Apenas uma publicação apresentava um questionamento como objetivo do estudo. A maioria dos artigos selecionados teve o local da pesquisa em escolas públicas e/ou universidades. Em relação ao tipo de periódico nas quais foram publicadas três estão indexadas na REBEn, duas na Psicologia em Estudo, duas na Ciência, Cuidado e Saúde, duas no Caderno de Saúde Pública, a outra na Revista Saúde Pública e a última na Ciência e Saúde Coletiva.

Quanto ao delineamento da pesquisa, seis artigos apresentaram abordagem qualitativa, quatro desenvolveram estudos com métodos quantitativos, um artigo de reflexão e uma revisão de literatura.

Os autores descreveram diversos conceitos sobre gênero, sexualidade, sexo, identidade sexual e homossexualidade, muita das vezes fazendo um resgate histórico sobre a homossexualidade desde década de 70 e desvelando problemáticas ainda presentes, como a discriminação e o preconceito.

Apenas um artigo descreve a importância da enfermagem diante da saúde do homossexual do gênero masculino, o que revela uma escassez no que se refere às publicações sobre esta temática e a pouca atenção, zelo e abertura diante das minorias sexuais. Isso pode ser avaliado no momento da coleta de dados onde se observou um grande déficit de artigos na área de enfermagem no que tange a importância da assistência de enfermagem a essas minorias.

Sendo assim, sabe-se que é necessário incluir o homossexual em nossos planos de assistência, de forma que ela contemple na vivência do dia-a-dia dos profissionais de enfermagem, e desperte os profissionais de enfermagem para um cuidar que acolha estas pessoas sem preconceito e com respeito, desenvolvendo um cuidado humanizado, pois, a essência da enfermagem é cuidar do ser humano independente de suas orientações sexuais.

\section{Discussões}

\section{Confrontando os aspectos conceituais}

Percebe-se que diante das discussões dos autores, vários aspectos conceituais convergiram, e foram poucos os que entraram em divergência. Quando trabalhado o conceito de homossexualidade uma gama de indagações emergiu-se, pois esse não é um conceito que se encontra pronto, estagnado, mas sim, um conceito que é discutido em várias linhas de pesquisa como a sociologia, antropologia, psicologia, neurociência, biologia e até mesmo teológica.

De acordo com os artigos 7, 9 e 11 trabalhados nesse estudo, a homossexualidade é definida como a preferência sexual por indivíduos do mesmo sexo. Porém, este conceito é um tanto vago, já que o termo preferência pode conotar a tendência a escolher, optar, e acaba não incluindo os processos biopsicosociocultural que podem determinar essa escolha $a^{1 ; 4 ; 6}$.

O termo homossexualidade é uma invenção do século XIX, pois antigamente as relações sexuais com pessoas do mesmo sexo eram denominadas de sodomia. Foi a partir da segunda metade do século que esta prática passou a ser uma categoria e nomeado como desvio da norma ${ }^{1}$. 
O estudo seis $^{9}$ entende que o desejo sexual deriva de uma construção individual que cada um faz da leitura e vivenciados elementos disponibilizado pelo meio social, como família, escola, vizinhança, mídia entre outras. Logo a homossexualidade deve ser compreendida como uma orientação e não como uma escolha.

Muitas pessoas têm a idéia pré-concebida de que a humanidade toda é heterossexual e que uma minoria de indivíduos encontra-se viciada num comportamento homossexual. Assim, acreditam que a homossexualidade é simplesmente, um comportamento anticonvencional que muitas pessoas escolhem externar. Outros indivíduos acreditam que a homossexualidade é uma das orientações sexuais normais, ou seja, o indivíduo simplesmente é (componente inato), não opta 1;:;10.

A orientação sexual é sinônima de identidade sexual uma vez que a mesma significa a atração afetiva e/ou sexual que uma pessoa sente pela outra. No entanto, embora tenha-se possibilidade de escolher se vamos demonstrar, ou não, os nossos sentimentos, os psicólogos não consideram que a orientação sexual seja uma opção passível de ser modificada por um ato da vontade ${ }^{11}$.

O Programa Brasil sem Homofobia trabalha conceitos gerais relacionados às minorias sexuais onde revelam que Gays são indivíduos que, além de se relacionarem afetivamente e sexualmente com alguém do mesmo sexo, tem um estilo de vida de acordo com sua preferência, vivendo sua sexualidade abertamente².

Por outro lado, os Travestis seriam os homens no sentido fisiológico que se relacionam com o mundo como mulher. Já os transexuais são pessoas que não aceitam o sexo que ostentam anatomicamente sendo o fator psicológico 0 predominantemente na transexualidade, pois o individuo identifica-se com o sexo oposto, embora dotado de genitália externa e interna de um único sexo².

Percebe-se diante do confronto conceitual que essas categorias são generalizantes e englobantes, pois acabam sendo vistas como minorias sexuais, o que pode ser muito importante politicamente, já no lado da descoberta da sexualidade pode não ser tão interessante para o indivíduo se ver neste emaranhado de identidades ${ }^{10}$.

Contudo, alguns autores discorrem que a escolha do objeto nem sempre serve de base para identidade, ou seja, não é somente a atração por pessoas do mesmo sexo que irá configurar a homossexualidade masculina. Se assim fosse a bissexualidade pareceria ser uma identidade insegura, e excluíam-se as transexuais e travestis que vivem sua sexualidade através de atividades e prazeres mais do que a simples preferência de gênero ${ }^{6 ; 9}$.

Conforme visualizado, a homossexualidade é entendida em vários sentidos seja no aspecto biogenético, religioso, medico ou sociocultural.

\section{O papel da enfermagem frente os direitos sexuais e reprodutivos do homossexual do gênero masculino}

Dentre as novas práticas, saberes, grupos e sujeitos assistidos pelo enfermeiro, está os homens, que representam uma grande demanda assistencial reprimida que necessitam ser priorizados durante a atenção individual ou coletiva por apresentarem uma série de necessidades, riscos e vulnerabilidades à sua saúde.

Partindo da premissa pautada no processo de enfermagem e na promoção da saúde, o papel do enfermeiro (a) frente à saúde do homossexual do gênero masculino é a educação em saúde, trabalhando a Política Nacional de Saúde Integral de Lésbicas, Gays, Bissexuais, Travestis e Transexuais em cima dos seus preceitos éticos e legais, pois esta é a chave para a melhoria da qualidade de vida desse público e é uma estratégia para redução do preconceito e discriminação ${ }^{12}$.

Devido à discriminação por orientação sexual e por identidade de gênero incidirem na determinação do processo saúde/ doença, assim como, no processo de sofrimento decorrente do preconceito e do estigma social a Politica de Saúde Nacional $\mathrm{LGBT}^{2}$ traça como objetivo promover a saúde integral de gays, bissexuais, travestis e transexuais, eliminando a discriminação e o preconceito institucional e social, bem como contribuindo para a redução das desigualdades e a consolidação do SUS como sistema universal, integral e equitativo.

Entre os objetivos específicos encontram-se melhorar o acesso aos serviços de saúde, qualificando a rede de serviços do SUS para uma atenção/cuidado integral à saúde das minorias sexuais, assim como, oferecer atenção e cuidado à saúde de adolescentes e idosos lésbicas, gays, bissexuais, travestis e transexuais oferecendo uma atenção integral nas DSTs, HIV, AIDS, hepatites virais e prevenção dos novos casos de câncer de próstata entre gays, homens bissexuais, travestis e transexuais.

A Politica Nacional LGBT$^{2}$ ainda prega na garantia dos direitos sexuais e reprodutivos das minorias sexuais, assegurando também, os direitos na saúde suplementar, com vistas à extensão da cobertura dos planos e seguros privados de saúde ao cônjuge dependente para casais de lésbicas, gays e bissexuais.

Reduzir os problemas relacionados à saúde mental, drogadição, alcoolismo, depressão e suicídio entre lésbicas, gays, bissexuais, travestis e transexuais, atuando na prevenção, promoção e recuperação da saúde são também focos da Política, 
bem como, a realização de ações educativas nas rotinas dos serviços de saúde voltadas à promoção da auto-estima entre as minorias sexuais e à eliminação do preconceito por orientação sexual, identidade de gênero, raça, cor e território, para a sociedade em geral².

Outro ponto fundamental para cumprir os princípios da Política Nacional LGBT e a Política Nacional de Humanização (PNH) melhorando a qualidade da atenção integral das minorias sexuais é capacitar os profissionais de saúde, integrantes das equipes da Estratégia Saúde da Família (ESF), para o melhor acolhimento das minorias sexuais nos serviços, incluindo na educação permanente temas ligados às especificidades desse público, promovendo assim, a melhoria das condições de saúde dos homens brasileiros ${ }^{12}$.

Na maioria das vezes, quando se fala em educação em saúde, pensasse logo em cuidados pessoais que tem como finalidade evitar doenças, como se a saúde das pessoas não estivessem ligadas a outros fatores, fosse um problema individual, e nessa ótica, muitos acreditam que os problemas podem ser resolvidos apenas pela educação individual, pessoal ${ }^{13}$.

Aeducação em saúde deve pressupor uma combinação de oportunidades que deve ter como finalidade maior a manutenção e promoção da saúde. Para ela essa educação deve ser entendida não somente como mera transmissão de conteúdos e sim como a adoção de práticas educativas que vise à autonomia dos sujeitos envolvidos na condução de sua vida ${ }^{13}$.

Sendo assim, pode-se dizer que a educação em saúde nada mais é que o pleno exercício de construção e consolidação da cidadania.

Os profissionais de enfermagem têm desempenhado um papel importantíssimo na questão da educação em saúde. No entanto, na sua prática cotidiana ainda existem algumas limitações principalmente nas questões referentes à educação do gênero masculino diante da homossexualidade ${ }^{14}$.

A enfermagem ainda não está habilitada a abordagem desse público em questão, mas que a mesma, através da educação em saúde, objetiva desmistificar alguns preconceitos e tabus ${ }^{14}$.

De acordo com a Politica LGBT, os direitos sexuais são: Direito de viver e expressar livremente a sexualidade sem violência, discriminações e imposições e com respeito pleno pelo corpo do(a) parceiro(a); Direito de escolher o(a) parceiro(a) sexual; Direito de viver plenamente a sexualidade sem medo, vergonha, culpa e falsas crenças; Direito de viver a sexualidade independentemente de estado civil, idade ou condição física; Direito de escolher se quer ou não quer ter relação sexual; Direito de expressar livremente sua orientação sexual: heterossexualidade, homossexualidade, bissexualidade, entre outras; Direito de ter relação sexual independente da reprodução; Direito ao sexo seguro para prevenção da gravidez indesejada e de DST/HIVIAIDS; Direito a serviços de saúde que garantam privacidade, sigilo e atendimento de qualidade e sem discriminação e direito à informação e à educação sexual e reprodutiva2; ${ }^{2}$.

A educação em saúde é uma combinação de oportunidades que favorecem a promoção e a manutenção da saúde. $A$ educação em saúde é a soma da transmissão de conteúdos com a adoção de práticas educativas que visem à autonomia dos sujeitos, ou seja, a construção da cidadania. Sendo assim, as práticas educativas se tornam essenciais para mudar estilos de vida prejudiciais que expõem os homens aos riscos ambientais e fisiológicos $2 ; 15$.

Portanto, torna-se indispensável promover a atenção à saúde do homossexual do gênero masculino de modo integral, a partir das redes de atenção em saúde, promovendo a integração sistêmica de ações e serviços de saúde com provisão de atenção contínua, integral, de qualidade, responsável e humanizada.

\section{Considerações finais}

A pesquisa integrativa possibilitou a percepção de que a homossexualidade do gênero masculino é pouco discutida pela literatura cientifica e que as políticas públicas de saúde, em especial, a Política Nacional de Saúde Integral de Lésbicas, Gays, Bissexuais, Travestis e Transexuais buscam resgatar esse público minoritário para a condução acessível e equitativa da saúde, melhorando sua qualidade de vida.

Percebeu-se que o papel do enfermeiro diante desse público é inerente as suas práticas assistenciais corriqueiras e que os mesmos não devem tomar medidas exclusivistas diante das minorias sexuais. A promoção, prevenção e reabilitação em saúde existem diante de qualquer sujeito, porém, devem-se levar em conta suas especificidades, por isso torna-se necessário atuar-se em cima dos princípios da integralidade, equidade, universalidade e humanização.

Como em todo processo educativo que exige estratégias de ação rumo à mudança de comportamento, a literatura deixa bem claro da necessidade de reformulação das práticas educativas e assistenciais em saúde no que se refere à conduta do enfermeiro frente ao homossexual do gênero masculino. 
O estudo evidenciou a importância de apreender sobre os direitos dos homossexuais, sobre as minorias sexuais e reprodutivas e principalmente sobre o papel da enfermagem diante desse público.

Sendo assim, é valido acreditar que a educação em saúde consiste em um dos principais elementos da promoção da saúde e, portanto, é uma ferramenta essencial para a prevenção, orientação e desmistificação de conceitos e tabus que muitas das vezes acabam denegrindo este público.

A conclusão de um trabalho acadêmico não pode encerrar-se nas suas conclusões, mas abrir possibilidades para uma reflexão acerca do que se vivenciou durante o seu desenvolvimento e a partir do conhecimento construído através dele. Com base nesse conhecimento, pode-se entender a urgência do aprimoramento de novos saberes que viabilizem concepções e práticas sociais mais eficazes.

\section{Referências bibliográficas}

1. Scott J. Gênero: uma categoria útil de análise histórica. IN: Mulher e realidade: mulher e educação. Porto Alegre: Vozes, V. $16 n^{0} 2$, jul/dez de 1989.

2. Brasil MS. Politica Nacional de Saúde Integral LGBT. Brasília, 2010.

3. Paiva V, Aranha F, Bastos F. Opiniões e atitudes em relação à sexualidade: pesquisa de âmbito nacional, Brasil 2005. Rev Saúde Pública, 42(Supl 1):54-6: 2008.

4. Menezes ABC, Brito RCS. Reflexão sobre a homossexualidade como

Subproduto da evolução do prazer. Psicologia em Estudo, Maringá, v. 12, n. 1, p. 133-139, jan./abr: 2007.

5. Rios LF. Corpos e prazeres nos circuitos de homossociabilidade masculina do Centro do Rio de Janeiro. Ciência \& Saúde Coletiva, 13(2):465-475: 2008.

6. Mandú ENT. Consulta de enfermagem na promoção da saúde sexual. Rev Bras Enferm, Brasília (DF) nov/ dez;57(6):729-32, 2004.

7. Brasil MS. Política Nacional de Atenção Integral à Saúde do Homem - Princípios e Diretrizes. Brasília, 2008.

8. Simpson CA, Miranda FAN, Mundo MMS, Azevedo DM. Trajetória de vida de um homossexual: entre o silêncio e a opressão. Cienc Cuid Saude, Vol. 6(4):424-432; 2007.

9. Salomé GM, Espósito VHC, Moraes ALH. O significado de família para casais homossexuais. Rev Bras Enferm, Brasília 2007 set-out; 60(5): 559-63.

10. Silva LMP. Experiências plurais em categorias singulares: problematizando a materialização das travestilidades. Fazendo o Gênero 8 - Corpo, violência e poder, Florianópolis, 2008.

11. Mendes KDS, Silveira RCCP, Galvão CM. Revisão integrativa: método de pesquisa para a incorporação de evidências na saúde e na enfermagem. Texto Contexto Enferm. 2008; 17(4):758-64.

12. Rios LF. Parcerias e práticas sexuais de jovens homossexuais no Rio de Janeiro. Cad. Saúde Pública, Rio de Janeiro, 19(Sup. 2):S223-S232, 2003.

13. Matoso LML, Castro CHA. Indissociabilidade clínica e epidemiológica da pneumonia. Catussaba, ano 2, n 2, p.11-23. 2013. 14. Palma YA, Levandowski DC. Vivências pessoais e familiares de homossexuais femininas. Psicologia em Estudo, Maringá, v. 13, n. 4, p. 771-779; 2008.

15. Nogueira JA, Almeida SA. Diversidade sexual no contexto escolar: percepção e atitudes dos educadores. Cienc Cuid Saude $2011 \mathrm{Jul} / \mathrm{Set} ; 10(3): 459-466$.

\section{Leonardo Magela Lopes Matoso}

Endereço para correspondência - Rua Elis Regina, n.170. Bairro Abolição IV, CEP 59614-100, Mossoró, RN, Brasil.

E-mail: leonardo.I.matoso@gmail.com

Lattes: http://lattes.cnpq.br/2525968153754172

\section{Enviado em 27 de junho de 2013.}

\section{Publicado em 26 de novembro de 2013.}

